\title{
La metáfora esponsal y la caracterización de Jesús en el cuarto evangelio
}

\author{
The Nuptial Metaphor and the Characterization \\ of Jesus in the Fourth Gospel
}

\author{
Miguel Ángel Garzón-Moreno \\ Facultad de Teología San Isidoro de Sevilla \\ garzon.co@hotmail.com (Id ORCID 0000-0003-1835-2496) \\ Álvaro Pereira-Delgado \\ Facultad de Teología San Isidoro de Sevilla \\ alvaropereira@sanisidoro.net (Id ORCID 0000-0002-7124-0162)
}

\begin{abstract}
Resumen: En el cuarto evangelio, la caracterización mesiánica de Jesús como el esposo lo diferencia de Juan el Bautista, que es solo — y nada menos que- "el amigo del esposo". Además, la trasferencia de los rasgos esponsales que Yahvé tenía en el Antiguo Testamento a Jesús invita a pensar en una"cristología alta". En la presente investigación, tras describir someramente el uso de la simbología nupcial en el Antiguo Testamento y en las tradiciones jesuánicas de la Iglesia naciente, estudiaremos diversos textos del cuarto evangelio (Jn 1,26-27; 2,1-11; 3,22-30; 4,4-42; 12,1-11; 20,1.1118) en los que la metáfora nupcial es empleada con diferentes matices. Iremos describiendo el diálogo intertextual que se genera en estos pasajes entre el modelo bíblico del que se parte y la apropiación creativa del evangelista. Concluiremos con algunas consecuencias para el quehacer de la cristología hoy a partir de la caracterización de Jesús como el Mesías esposo.
\end{abstract}

Palabras claves: Evangelio de Juan, metáfora nupcial, Cristo esposo, Juan el Bautista, simbología joánica

\begin{abstract}
In the fourth gospel, the messianic characterization of Jesus as the bridegroom differentiates him from John the Baptist, who is only - and no less than - "the friend of the bridegroom". Furthermore, the transfer of the nuptial features that Yahweh had in the Old Testament to Jesus suggests a "high Christology". In the present research, after briefly describing the use of nuptial symbolism in the Old Testament and in the early jesuanic traditions, we will study various texts of the fourth Gospel (Jn 1,26-27; 2,1-11; 3,22-30; 4,4$42 ; 12,1-11 ; 20,1.11-18)$ in which the nuptial metaphor is used with different nuances. We will describe the intertextual dialogue that is generated in these passages between the biblical models on which they are based and the creative appropriation of the evangelist. We will conclude with some consequences for the current task of Christology.
\end{abstract}

Keywords: Gospel of John, nuptial metaphor, Christ the bridegroom, John the Baptist, Johannine Christology 
He aquí el Esposo que viene en medio de la noche; dichoso el siervo al que encontrará velando, indigno al que encontrará negligente. Mira, pues, alma mía, que el sueño no te venza, para que no seas entregada a la muerte y encerrada fuera del Reino; sino que, velando, clama: "Santo, Santo, Santo eres, oh Dios, por la Madre de Dios ten piedad de nosotros"1.

Los tres primeros días de la Semana Santa en la liturgia ortodoxa son llamados" "los días del Esposo". El Domingo de Ramos por la tarde

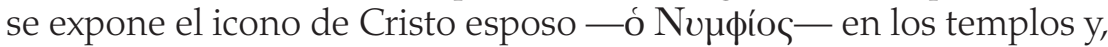
en la celebración de las laudes, se canta el tropario que acabamos de citar $^{2}$. En Occidente, si bien las tradiciones monástica y mística han reparado con frecuencia en el amor esponsal de Cristo, este título tan sugerente apenas ha tenido incidencia en la reflexión cristológica y en la pastoral eclesial ${ }^{3}$. En el presente estudio trataremos de ofrecer algunas bases escriturísticas para la elaboración de una cristología esponsal. Comenzaremos por describir brevemente la simbología nupcial en la Escritura y, tras identificar cómo se gestó la idea en el cristianismo naciente, nos detendremos en el uso de la metáfora en el cuarto evangelio. La originalidad de nuestro ensayo no radica en ofrecer nuevas propuestas de interpretación, sino en la búsqueda de una síntesis que pueda ser útil a teólogos y evangelizadores.

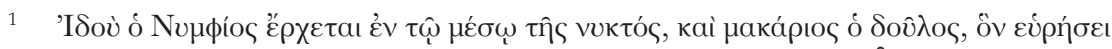

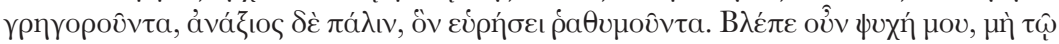

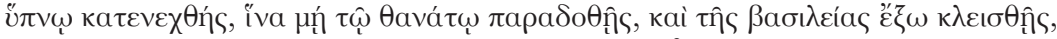

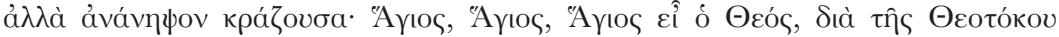

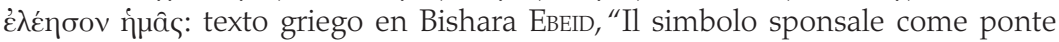
tra le tradizioni greca e siriaca. Un approccio patristico-liturgico. Parte seconda", Liturgia Sacra 22 (2016) 445 nota 67; la traducción es nuestra.

2 En la antífona de laudes de la Epifanía del Señor del rito romano, Cristo también es descrito como el esposo de la Iglesia:"Hoy la Iglesia se ha unido a su Celestial Esposo, porque, en el Jordán, Cristo la purifica de sus pecados; los magos acuden con regalos a las bodas del Rey, y los invitados se alegran por el agua convertida en vino".

3 Pedro Luis Vives Pérez, "Cristo, esposo de la Iglesia”, Facies Domini 3 (2011) 111127, constata este olvido y hace una síntesis de la obra de Vincenzo BatTaGLia, Il Signore Gesù Sposo della Chiesa. Cristologia e contemplazione, Bologna, Dehoniane, 2001, para mitigar esta ausencia. 


\section{LA SIMBOLOGÍA ESPONSAL EN LAS ESCRITURAS DE ISRAEL}

Las experiencias universales del enamoramiento y de la vida marital sirvieron a Israel para ilustrar sus relaciones de alianza con Dios. En el uso más típico de esta metáfora, Yahvé ocupa el rol del esposo y el pueblo (Israel, Jerusalén, Sion, etc.) el de la esposa. Los textos y sus matices son múltiples: si el Cantar de los Cantares — que debe ser leído primero de forma literal - se detiene en el enamoramiento apasionado y en la belleza de los novios, el Salmo 45 (o Isaías 61,10-11; 62,1-5, etc.) celebra la alegría de la boda. Con todo, la experiencia del amor no siempre es hermosa y complaciente: los profetas, comenzando por Oseas, tomaron pie de la experiencia dramática de la infidelidad conyugal para formular el disgusto divino por los devaneos idolátricos del pueblo. Oseas (1-3) desarrolla el paralelismo entre el profeta engañado por su mujer infiel y el esposo Yahvé cuya esposa — su pueblo— se ha prostituido con otros dioses, generando hijos de prostitución. La metáfora será retomada por Is 1,21 (también es evocada en el canto de la viña de Is 5,1-7), por Jeremías (2-3) y, especialmente, por los amplísimos desarrollos de Ezequiel 16 y 23, que describen, con tintes alegorizantes, la historia de la alianza entre el Señor y su pueblo a partir de la dura categoría de la prostitución ${ }^{4}$. Las terribles requisitorias de Ezequiel contra la prostituta Jerusalén alcanzan tonos tan patéticos como los siguientes:

${ }^{30}$ ¡Qué inquieto estaba tu corazón —oráculo del Señor Dios- cuando hacías todas esas cosas, propias de una prostituta descarada, ${ }^{31}$ cuando construías tu alcoba en cada cabecera de caminos, y tu lugar de culto en cada plaza! Ni siquiera fuiste como una prostituta. Tú desdeñabas la paga, ${ }^{32}$ como mujer adúltera que, en lugar de acoger a su marido, acoge a los extraños. ${ }^{33} \mathrm{~A}$ una prostituta se le paga con regalos, pero tú has dado tus regalos a todos tus amantes y los has seducido para que vinieran a ti de todas partes para tus prostituciones. ${ }^{34}$ Te ha ocurrido en tus prostituciones lo contrario que a otras mujeres, justo al contrario: como nadie te solicitaba, pagabas tú en lugar de ser pagada.

(Ezequiel 16,30-34)

4 Se puede consultar una síntesis sobre los diferentes matices de la prostitución en el Antiguo Testamento en Phyllis A. BIRD, "Prostitution in the Social World and Religious Rhetoric of Ancient Israel", in Christopher A. FARAONE - Laura K. McClure (eds.), Prostitutes and Courtesans in the Ancient World, Madison (WS), The University of Wisconsin Press, 2006, 40-58. 
En el proceso generador de esta metáfora influyó la negativa de la Ley a los cultos de la fertilidad de los vecinos cananeos, a partir de los cuales los devotos tenían relaciones con las prostitutas sagradas (hieródulas) para implorar a sus dioses la fecundidad de los ganados y sus mujeres (Deut 23,19).

Ahora bien, los profetas no solo emplearon la simbólica esponsal en los oráculos de denuncia. También dieron un giro inesperado a la dinámica de la infidelidad para anunciar la restauración escatológica de la alianza. Si en el plano legal y fáctico el varón que había repudiado a una mujer en ningún caso podía volver a tomarla por esposa, pues permanecía impura para él (Deut 24,1-4; Jer 3,1-4), en el plano religioso y simbólico el esposo Yahvé sí ofrece una nueva oportunidad a su pueblo infiel (Os 2,16-25; Is 50,1; 54,1-10; 62,4-5; Jer 3,12-13; 31,21-22; Ez 16,59-63). Dios realiza este milagro de gracia que restaura la pureza de su pueblo adúltero. Un nuevo inicio es posible en el amor entre Yahvé y los suyos, por puro favor divino.

En la tradición sapiencial, el símbolo matrimonial también fue usado para ilustrar el amor del joven estudiante por la Sabiduría, su novia y esposa (Prov 4,5-9; Eclo 6,18-31; 14,20-15,10; 51,13-30; Sab 8,2-3.9-21; etc.). Cambian aquí algunos elementos de los pasajes anteriores: el papel humano no lo ocupa una colectividad (el pueblo, Jerusalén, Sion) sino un individuo, el aprendiz que desea la sabiduría. Además, los roles se invierten: el papel masculino es ocupado por el fiel que busca a la amada y femenina Sabiduría ${ }^{5}$.

Los textos revelan muchos matices ${ }^{6}$. Aunque no podemos detallarlos, sí que es pertinente indicar cuatro elementos, que después reaparecerán en nuestra presentación sobre la metáfora esponsal en el cuarto evangelio.

5 A pesar de que este dato es signo de una cultura patriarcal donde solo los varones estudiaban, también aparecen mujeres sabias en la Escritura, como la prudente Abigail (1 Sam 25), la viuda de Técoa (2 Sam 14), la mujer "sagaz" y"de buen juicio" de Abel Bet Maacá (2 Sam 20,16-26), la reina de Sabá (1 Re 10) o la esposa sensata de Prov 31.

6 Para profundizar, cf. Luis Alonso SchÖKel, Símbolos matrimoniales en la Biblia, Estella, Verbo Divino, 1997; y Luca Pedroli (ed.), L'analogia nuziale nella Scrittura. Saggi in onore di Luis Alonso Schökel, Roma, GBP, 2019. También es recomendable la obra de Carlos GranADOs, El camino del hombre por la mujer. El matrimonio en el Antiguo Testamento, Estella, Verbo Divino, 2014, que estudia la metáfora nupcial aplicándola a las relaciones maritales entre el hombre y la mujer. 
a) Belleza y simbolismo. El amante, si está enamorado, admira la belleza de su amada. La novia del Cantar, vergonzosa, se presenta como "morena", es decir, bronceada por el rudo trabajo del campo,

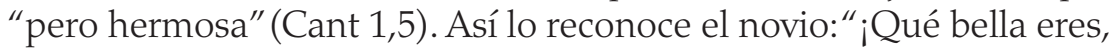
amada mía, qué bella eres!" (Cant 1,15). En general todo el poema es un rosario de piropos en el que los amantes se gozan en las bellezas del otro (Cant 1,12-2,7; 4,1-15; 5,10-16; 6,4-12; etc.). Igualmente, en el Salmo 45 se pondera la belleza del rey esposo y de su nueva esposa, recurriendo a vestidos, joyas, perfumes, espacios suntuosos y cantos inspirados. La naturaleza también sirve como reflejo simbólico para ensalzar la belleza del otro. Por ejemplo, el agua es signo de amor y fidelidad en Prov 5,15 y Cant 4,15. También Ef 5,26-27 y Jn 3,22-30 relacionarán el bautismo con el matrimonio, un tipo de baño nupcial.

b) Intimidad y exclusividad. La relación esponsal implica llegar a ser "una sola carne" (Gén 2,24) ${ }^{7}$, por eso la amada del Cantar canta llena de alegría: "Mi amado es mío y yo soy suya" (Cant 2,16; 6,3; $7,11)$. Pero la intimidad conlleva exclusividad. Por eso la metáfora esponsal sirvió a los profetas para denunciar la idolatría, el culto a otros dioses, rivales del Señor. Dios, como esposo injuriado, denunciaba a su esposa, mujer adúltera (Os 1-3) y prostituta díscola que se entregaba a otros amantes (Jer 2-3; Ez 16; 23; etc.).

c) Fecundidad. Asimismo, el amor esponsal implica la fecundidad (o no) de una relación que genere nuevos hijos. La pareja original recibió el mandato de la fecundidad (Gén 1,28) y los relatos bíblicos están plagados de historias acerca de la búsqueda denodada del hijo (Abrahán y Sara deseando a Isaac; Raquel, y sus envidias por la fecunda Lía, etc.). A nivel simbólico, Sion (Jerusalén...) es también descrita como una mujer que anhela ansiosa hijos: Jer 31,15, en negativo; o 66,7-14, en positivo, cuando Dios da hijos a Sion, cuyas ubres abundantes alimentan a su nueva progenie (cf. Is $54,1-3)^{8}$.

d) Tiempo y espera. Los textos bíblicos revelan sobre el amor que es, ante todo, historia de amor. En el Cantar de los Cantares los amantes se esperan, se buscan, se desean impacientes, se presienten, se encuentran y desencuentran. El tiempo es la prueba del amor. En los oráculos proféticos, el drama de la infidelidad tiene un pasado,

\footnotetext{
7 Son muy esclarecedoras las páginas de GRANADOs, El camino del hombre por la mujer, 31-41, sobre esta expresión bíblica.

8 Cf. Alonso SchÖKel, Símbolos matrimoniales, 187-240.
} 
"los días de la juventud" (Os 2,17; cf. Jer 2,2) donde la esposa-pueblo experimentó el amor gratuito; y un futuro, cuando Dios la "lleve al desierto"y vuelva a desposarla para siempre (Os 2,16-25). El Esposo divino es capaz de restaurar lo destruido y alumbrar caminos imposibles en su alianza de amor. Por otro lado, el amante experimenta siempre una ambivalencia entre la grandeza de sus amores actuales y una cierta insatisfacción, un anhelo siempre mayor. Esta ambivalencia implica que el amante suele tener la sensación de que en esta tierra no se pueden saciar sus deseos y, sin embargo, las bodas son ya signo de plenitud cimera, de eternidad. Los textos bíblicos son sensibles a dicha ambivalencia. En el Cantar los momentos de encuentro se alternan con otros de impaciencia anhelante. También Jesús dice que en el cielo ni los hombres ni las mujeres se casarán, señalando el carácter provisorio del amor matrimonial (Mc 12,25), pero usa la imagen del banquete de bodas para referirse a la plenitud del reino de los cielos (Mt 22,1-14; Lc 14,16-24). En fin, el Apocalipsis se cierra con un clamor expectante que ansía la comunión final: "El Espíritu y la esposa dicen: «ven»" (Ap 22,17). Pasemos, así pues, a los escritos del Nuevo Testamento.

\section{LA SIMBOLOGÍA ESPONSAL EN LA TRADICIÓN CRISTIANA NACIENTE}

Al igual que con los textos del Antiguo Testamento, nuestra presentación acerca de la simbología esponsal en la tradición cristiana previa al cuarto evangelio será necesariamente concisa.

La imagen esponsal probablemente se transmitió ya en algunas tradiciones del Jesús histórico. El pasaje que trata acerca de la pregunta sobre el ayuno (Mc 2,18-20; Mt 9,14-15; Lc 5,33-35; EvTom 104) tiene muchos visos de hundir sus raíces en la predicación prepascual $^{9}$. Según Meier, el relato cumple con el criterio de discontinuidad,

9 Cf. John P. MeIer, Un judío marginal. Nueva visión del Jesús histórico, Tomo II/1: Juan y Jesús. El reino de Dios, Estella, Verbo Divino, 2001, 529 (521-534), a partir del texto de Mc, reconstruye la posible tradición originaria así:"Y fueron a decirle a Jesús: «¿por qué los discípulos de Juan ayunan, pero tus discípulos no ayunan?». Jesús les dijo: «ipueden los invitados a la boda ayunar cuando el novio está con ellos?»”. En otro sentido, Rainer RIESNER, “The Question of the Baptist's Disciples on Fasting (Matt 9:14-17; Mark 2:18-22; Luke 5:33-39)", in Tom Holmén - Stanley E. Porter (eds.), Handbook for the Study of the Historical Jesus. 
ya que era extraña en el judaísmo de la época y entre las primeras comunidades esta norma de los discípulos de Jesús de no practicar el ayuno voluntario, merced a la convicción escatológica de que el reino de Dios había comenzado. Además, este hábito contracultural era coherente con otros dichos y hechos del Jesús histórico, quien comía con publicanos y al que llamaban comilón y borracho (Lc 7,31-34; Mt 11,16-19). Los estudiosos han notado que el símil del esposo no es una simple comparación. Aunque sea solo de manera muy germinal, hay ya cierta pretensión de identificar a Jesús con un personaje señero, el novio. En este sentido, la preferencia por la expresión "cuando el novio está con ellos", en vez del más simple "durante la boda", sugiere que"de un modo oblicuo o enigmático, Jesús intenta aludir a su propia condición de proclamador profético - y en cierto sentido realizador - del reino. Sin Jesús, sus discípulos no conocerían la alegría de un continuo banquete de boda ni se sentirían autorizados, a causa de ese convite, a rechazar todo ayuno voluntario"10.

Además de esta tradición que probablemente hunde sus raíces en la predicación del Jesús histórico, la existencia de dos parábolas diferentes acerca del reino de Dios como banquete de bodas - la parábola de los invitados al banquete (Mt 22,1-14; Lc 14,16-24, aunque en la versión de Lucas no aparece el elemento nupcial; EvTom 64) y la parábola de las diez vírgenes (Mt 25,1-13) — sugiere que muy pronto la simbología nupcial se incorporó a la tradición de los dichos de Jesús. En fin, el dicho del Bautista sobre las sandalias, que cumple el criterio de la atestiguación múltiple (Mc 1,7; Mt 3,11; Lc 3,16; Jn 1,27), si es interpretado a la luz de la ley del levirato, también podría ser un testigo de la tradición del Mesías esposo ${ }^{11}$. Volveremos a este pasaje más adelante.

También las cartas paulinas emplean la simbología nupcial para esclarecer la identidad de Jesús y su relación con los creyentes. En

Part Four: Individual Studies, Leiden, Brill, 2011, 3311 (3305-3347), considera la versión común a Mt y Lc más antigua y propone, en consecuencia, la siguiente reconstrucción de la tradición originaria: “Pueden los hijos de la cámara nupcial ayunar cuando el esposo está con ellos? Pero llegarán días cuando el esposo sea arrebatado de ellos, entonces ellos ayunarán en tales días".

10 MeIER, Un judío marginal, Tomo II/1, 532.

11 Luis Sánchez-Navarro, "Gesù, il Messia Sposo. La testimonianza del Sinottici", in Pedroli, L'analogia nuziale, 69-74 (67-91), intenta probarlo con bastantes argumentos. 
un pasaje de las cartas protopaulinas, Pablo describe a la Iglesia de Corinto como virgen casta que él ha dado en matrimonio a Cristo, su único esposo, e intenta con mucho celo guardarla incólume hasta su vuelta gloriosa (2 Cor 11,2-3). Aunque algunos padres de la Iglesia leyeron en paralelo 2 Cor 11,2-3 y Jn 3,29-30, de manera que Pablo, como Juan Bautista, haría las veces del amigo del esposo; sin embargo, el motivo de los celos divinos, de hondas raíces bíblicas (Éx 34,14; Deut 4,24, etc.), y algunos paralelos de las cartas hacen pensar mejor en el rol de Pablo como el padre de la comunidad (1 Cor 4,15; 2 Cor $6,13 ; 12,14)$, que trata de preservar a su doncella ante las acechanzas de otros amores ${ }^{12}$. En las cartas deuteropaulinas, la simbología nupcial es retomada en el código doméstico de Efesios 5,25-27. De manera más explícita que en 2 Corintios se desarrolla aquí una amplia tipología entre el tipo Adán y Eva, el antitipo Cristo y la Iglesia y la aplicación a los esposos cristianos. En este texto la simbología nupcial traspasa los límites de la analogía y se convierte en el verdadero misterio de la realidad.

Finalmente, la conclusión del libro del Apocalipsis desarrolla ampliamente el motivo escatológico de las bodas del Cordero - como anuncio en 19,7-9; y como celebración en 21,1-22,5- con la esposa Iglesia, que tiene la doble valencia de ser la comunidad presente que grita "¡ven!" $(22,17)$ y que es también la Jerusalén celeste, plenitud escatológica deseada $(21,2.9)^{13}$.

En conclusión, el desarrollo de la metáfora esponsal para caracterizar a Jesús en el cuarto evangelio tiene como precedente una tradición que, con bastante probabilidad, hunde sus raíces en el propio Jesús histórico, quien utilizaría la simbología esponsal para referirse al nuevo tiempo del Reino. Además, tanto la apropiación sinóptica como la paulina ahondaron ya en esta tradición identificando a Jesús como el Mesías esposo.

12 Así Murray J. Harris, The Second Epistle to the Corinthians. A Commentary on the Greek Text (NIGTC), Grand Rapids (MI) - Milton Keynes, Eerdmans - Paternoster, 736-737; y Antonio PIтTA, La seconda lettera ai Corinzi, Roma, Borla, 2006, 434435, entre otros muchos.

13 Cf. Luca Pedroli, Dal fidanzamento alla nuzialità escatologica. La dimensione antropologica del rapporto crescente tra Cristo e la Chiesa nell'Apocalisse (Studi e Ricerche. Sezione biblica) Assisi, Cittadela, ${ }^{2} 2015$. 


\section{LA SIMBOLOGÍA ESPONSAL EN EL CUARTO EVANGELIO}

El cuarto evangelio bebe de la tradición bíblica sobre la simbología nupcial que hemos ido identificación en los textos precedentes, pero la desarrolla creativamente. Al decir de Zimmerman, "el verdadero logro teológico y lingüístico del evangelio de Juan no estriba en su conocimiento de las Escrituras, sino en su potencial creativo para desarrollar y aplicar las redes metafóricas de manera significativa"14.

Comenzaremos, a continuación, por explicar el único texto explícito en el que Jesús es caracterizado como el esposo (Jn 3,22-30). Seguidamente iremos identificando los matices de este motivo en otros pasajes del cuarto evangelio.

\section{1. "El que tiene a la esposa es el esposo" $(\mathrm{Jn} 3,29)$}

El único texto del cuarto evangelio en el que Jesús es designado de manera clara como esposo es Jn 3,22-30. Aquí el Bautista declara ante sus discípulos que"el que tiene a la esposa es el esposo" $(3,29)$. Él solo ocupa el rol del amigo del esposo que prepara a la esposa-pueblo para la alegría del encuentro nupcial. Estas afirmaciones están en clara relación con el dicho de Jesús histórico, atestiguado por primera vez en Mc 2,19, en que Jesús era comparado a un esposo. Ahora bien, el texto de Jn 3,29 no depende de la tradición sinóptica, sino de una tradición autónoma que Trocmé y Riesner atribuyen a los círculos del Bautista ${ }^{15}$. Sea o no cierta esta apreciación, resulta relativamente seguro que el autor (o autores) del cuarto evangelio no crea(n) la asociación entre la metáfora nupcial y la identidad de Jesús, sino que la hereda(n) de la tradición.

Más concretamente, la escena de Jn 3,22-30 solo aparece en el cuarto evangelio ${ }^{16}$. Tras el diálogo nocturno en Jerusalén entre Jesús

14 Ruben Zimmerman, "Jesus - the Divine Bridegroom? John 2-4 and Its Christological Implications" in Benjamin ReYNoLDs - Gabriele BocCACCINI, Reading the Gospel of John's Christology as Jewish Messianism. Royal, Prophetic, and Divine Messiahs (Ancient Judaism and Early Christianity 106), Leiden - Boston (MS), Brill, 2018, 381 (358-386).

15 Cf. Etienne Trocmé, "Jean 3,29 et le thème de l'époux dans la tradition présynoptique," Revue des sciences religieuses, 69 (1995) 13-18; y RIESNER, "The Question of the Baptist's Disciples", 3316-3319.

16 Cf. Roberto Martínez Rivera, El amigo del novio. Juan el Bautista: historia y teología (Estudios Bíblicos 70), Estella, Verbo Divino, 2019, 275-320, quien dedica un estudio enjundioso al pasaje. 
y Nicodemo sobre la necesidad de nacer de nuevo (3,1-21), el evangelista conduce a su lector a dos lugares del Jordán donde tanto Jesús como Juan están bautizando. Mientras Jesús bautiza más abajo, en Judea, la escena transcurre más arriba en Samaría, en Ainón, cerca de Salim ${ }^{17}$, donde el Bautista está con sus discípulos bautizando. Es la última vez que Juan aparece en escena en el cuarto evangelio. Podríamos decir que aquí el evangelista nos lega el testamento del Bautista. El narrador anuncia, de hecho, su final violento con una nota explicativa: "aún no había sido encarcelado" $(3,24)$. En sus últimas palabras, Juan el Bautista va a dar testimonio de Cristo como"el esposo que tiene a la esposa".

Tras la introducción de los vv. 22-24, la trama se pone en marcha cuando se desencadena una disputa sobre la purificación entre un judío ${ }^{18}$ y los discípulos de Juan. Ser puro o impuro era un tema importante en la época. La discusión aquí se refiere probablemente al valor purificador de los bautismos respectivos de Juan y Jesús ${ }^{19}$. La escena se desarrolla a partir de un diálogo entre el Bautista y sus discípulos. Del tema de la purificación se pasa a la pregunta por quién purifica: "todos" se van con Jesús y los discípulos de Juan le inquieren al interpretar este hecho como una pérdida de influencia de su maestro.

Antes de continuar con este asunto, es adecuado reparar en la conexión entre el tema de la purificación, el bautismo con agua y la

17 Los estudiosos discuten dónde localizar esta Ainón. Lo más probable es ubicarla en Samaría, en la actual Salim, en los contornos de Siquem, la actual Nablús. Algunos estudiosos han propuesto que se trataría de nombres simbólicos (Ainón:"fuentes"; Salim:"de salvación"). Sin embargo, hay buenas razones para pensar que, incluso si el evangelista repara en el valor simbólico de los nombres, se trate de localizaciones reales. Cf. Raymond E. BRown, The Gospel according to John I-XII (The Anchor Bible 29), Garden City, NY, Doubleday, 1966, 151.

18 Manuscritos valiosos (el Papiro 66, la primera mano del Códice Sinaítico, Orígenes, etc.) atestiguan el plural"judíos". Sin embargo, el singular es preferible porque es la lectio difficilior; y el plural sería generado por armonización con los demás pasajes de Jn donde siempre aparece "los judíos" en plural. Cf. Bruce M. Metzger, A Textual Commentary on the Greek New Testament, Stuttgart, Deutsche Bibelgesellschaft, ${ }^{2} 1994,175$.

19 Cf. Jean Zumstein, El evangelio según Juan (1-12) (Biblioteca de Estudios Bíblicos 152), Salamanca, Sígueme, 2016, 165. Según MARTínez Rivera, El amigo del novio, 304-303, la vaguedad de la expresión hace recaer el interés no tanto sobre el contenido de la discusión, sino sobre el hecho mismo de que discutieran. Este hecho reflejaría el antagonismo que probablemente surgió en el siglo i entre una facción de los seguidores de Juan y los discípulos de Jesús. 
metáfora nupcial. En el signo precedente de las bodas de Caná se mencionaron seis tinajas de piedra llenas de agua destinadas a las purificaciones de los judíos (Jn 2,6). Ya notamos en nuestros análisis precedentes que el agua estaba relacionada con la metáfora esponsal. En el universo nupcial, uno de los ritos previos a la boda era el lavabo, la mikvah de la novia. Ya en tiempos bíblicos, Noemí exhorta a Rut a que se lave antes de ir al encuentro de Booz en la era (Rut 3,3; cf. Ez 16,8-9); o, de manera más teologizada, en Ef 5,26, la mujer-Iglesia es purificada por Cristo, su esposo, mediante el baño del agua y la fuerza de la Palabra, para presentársela ante sí. De ahí que también en Jn 3,22-30 aparezca latente la idea de que la novia-pueblo es lavadapurificada para encontrarse con su Mesías esposo.

Volviendo al texto, Juan es interrogado por sus discípulos sobre Jesús. La pregunta de los discípulos no es neutra. Jesús aparece como un rival - los dos bautizan y a los dos les siguen discípulos- ¿ ¿Cómo reacciona Juan? ¿Lo considera su adversario? De ningún modo: el Bautista, según el cuarto evangelio, testimonia que él no es el Mesías, sino Jesús. Juan hace ver a sus discípulos que no se da un contraste entre dos maestros y sus doctrinas, sino entre dos épocas: la antigua y la nueva edad ${ }^{20}$. Por eso, el Bautista se va a reconocer solo - y nada menos que- el amigo del esposo, enviado a testimoniar la llegada del Mesías esposo que inaugura los tiempos nuevos.

Para expresarlo, el primer argumento de la respuesta del Bautista, con carácter de sentencia, incide en el origen divino de la labor de Cristo ("Nadie puede tomarse algo para sí si no se lo dan desde el cielo": 3,27; cf. Sal 5,3; 1 Cor 4,7). Jesús bautiza y todos se van con él porque Dios así lo ha dispuesto (cf. Jn 6,44). El Bautista no se puede oponer a ello.

El segundo argumento (Jn 3,28) recuerda la predicación precedente del Bautista. Juan ha dado testimonio de Jesús como Mesías y

20 En su homilía sobre Jn 3,22-29, predicada en Hipona en mayo del 407, san Agustín amplía la significación del contraste y toma pie de él y de Jn 1,16, para confesar la divinidad de Jesús: "No ignora Juan que precede a Cristo por su nacimiento; pero se confiesa inferior a Él; conoce que su salud es Cristo. Ya había dicho antes: Todos nosotros hemos recibido de su plenitud (Jn 1,16). Esto es confesar que es Dios. ¿Cómo todos los hombres reciben de su plenitud, si Él no es Dios? Porque, si aquel hombre es tal que no es Dios, Él recibe también de la plenitud de Dios, y así no es Dios. Mas, si todos los hombres reciben de su plenitud, la fuente es Él, y ellos los que beben" (Tratados sobre el evangelio de San Juan 13,8; BAC 139; obras completas de san Agustín, tomo XIII, p. 367). 
ha dejado claro que él solo es la voz que lo anuncia (Jn 1,19-34.3537). Así pues, que "todos" se vayan con Jesús no amenaza la vocación de Juan, sino que, muy al contrario, confirma su misión de testigo.

El tercer argumento (Jn 3,29), de tenor parabólico, emplea la simbología nupcial. Con ella, el Bautista aclara quién es él respecto del Mesías: Jesús, y no él, es el esposo"que tiene a la esposa". La nota de exclusividad que habíamos identificado en el uso profético de la metáfora nupcial aparece aquí en toda su relevancia. Juan no puede arrebatarle la esposa a Jesús, el esposo legítimo de la esposa-pueblo (y comunidad creyente). San Agustín llamará adulterio a la actitud contraria ${ }^{21}$. Por eso, lo dicho en Jn 3,27 ("Nadie puede tomarse algo para sí si no se lo dan desde el cielo") recibe aquí una nueva aplicación: ahora se comprende que el Bautista no puede arrogarse para sí el amor de la esposa-pueblo, pues Dios se la tenía reservada a su Mesías $^{22}$. Él tan solo ocupa el rol del amigo.

En las bodas del Mediterráneo antiguo, el amigo del esposo (en hebreo, el שושבין: shoshebin), era el responsable de acompañar a la novia desde la casa de su padre a la de su futuro marido, organizar la celebración y ser testigo del enlace, entre otros cometidos ${ }^{23}$. Es pre-

21 "Mirad que es adulterio amar a un hombre en lugar de Cristo. ¿A qué viene eso? Estad atentos a las palabras de Juan. Cabía el error acerca de Juan; podía ser tenido él mismo por el que no era; él rechaza lejos de sí este falso honor para asegurarse más en la firme verdad. Mirad lo que dice que es Cristo y lo que es Él. El que tiene la esposa es el esposo. Sed castos, amad al esposo. ¿Qué eres tú, que nos dices: El que tiene la esposa es el esposo? Mas el amigo del esposo, que está en pie delante de Él para oírle, se llena de gozo por la voz del esposo" (Tratados sobre el evangelio de San Juan 13,10; BAC 139; obras completas de san Agustín, tomo XIII, p. 369). El de Hipona aplica esta idea al dolor que siente porque los donatistas están siguiendo a un hombre y no a Jesucristo, cometiendo así una clase de adulterio.

22 Dice J. Ramsey Michaels, The Gospel of John (NICNT), Grand Rapids (MI) Cambridge, Eerdmans, 2010, 219, que el referente de la esposa no resulta claro en el pasaje, en continuidad con la ausencia de la esposa en otros textos en los que aparece la metáfora nupcial (Mc 2,19-20; Mt 22,1-14; Mt 25,1-13; y Jn 2,1-11). En nuestra opinión, este dato se debe a que, al menos en Jn 3,22-29, la discusión estriba en la identificación del Mesías —Jesús y no Juan-, mientras que la figura de la esposa permanece constante en la tradición: el pueblo.

23 Según Luca Pedroli, "La teoria del ninfagògo e il caso emblematico di Ef 5,2527", in Pedroli, L'analogia nuziale, 122-126 (121-152), el término שושבין ("amigo íntimo", "amigo fiel") proviene del verbo שבב ("estar unido", "ligarse"). En la Misná se dice que, a la hora de escoger jueces, es inhábil "el amigo de la boda" (m.Sanhedrin 3,4-5), ya que tiene un fuente lazo de unión con el novio. En el Talmud babilónico (Baba Batra 9,4; 144b), se dice que el esposo tendría que hacer 
cisamente lo que Juan hace: mediante un bautismo de purificación y un testimonio elocuente, Juan, el amigo del esposo, prepara y purifica a la esposa-pueblo, para presentarla ante su esposo, Jesucristo ${ }^{24}$.

La metáfora nupcial es alargada en Jn 3,29b para incidir en su valencia escatológica ${ }^{25}$. Antes decíamos que en la tradición bíblica el amor era siempre historia de amor, y que la simbología nupcial podía funcionar como indicio del anuncio escatológico. Así sucede aquí. Un juego intertextual contribuye a ello. La asociación de los términos "esposo", "esposa", "voz"y" alegría" recuerda un estribillo del libro de Jeremías (Jer 7,34; 16,9; 25,10; 33,11; cf. Bar 2,23; cf. Ap 18,25) ${ }^{26}$.

a su vez de shoshebin de su amigo, si se casa, y sufragar la fiesta de la boda.Y si el amigo se muriese, debería resarcir a la familia. De esta noticia comprendemos que el“amigo del novio"tenía, además de otras funciones (acompañar a la novia, testimoniar que se ha consumado el matrimonio, etc.), la de aportar dinero a la boda. La figura del amigo del esposo no pertenecía solo a la tradición judía; era una institución común en la cultura mediterránea en general. También en griego el $v v \mu \phi \alpha \gamma \omega \gamma o ́ \varsigma$ o $\pi \alpha \varrho \alpha ́ v v \mu \phi o \varsigma$ era el amigo que acompañaba a la novia desde su casa a la del esposo. En 1 Macabeos 9,37-40, se cuenta que Jonatán y Simón ten-

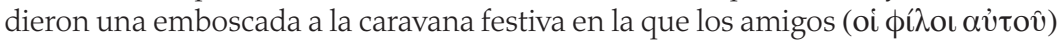

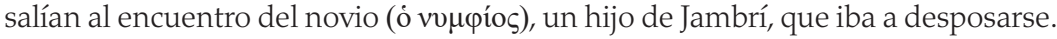

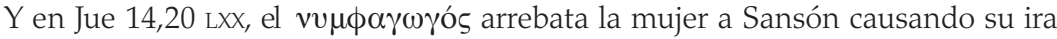
desmedida. Aunque ya sea desusado hoy, el diccionario de la Real Academia aún incluye en la voz"paraninfo" el significado"padrino de bodas". Cf. el estudio etimológico de Julián BRAVOVEGA, "Ninfa intertextual: actualización de un modelo literario", Aiso. Actas 6 (2002) 365-372.

24 Algunos estudiosos, sin embargo, cuestionan que realmente sea significativo el trasfondo del ninfagogo en este pasaje, porque el "padrino" de las bodas era más importante que el mismo novio, lo que iría contra el sentido del pasaje. Cf. Zimmerman, "Jesus — the Divine Bridegroom?", 361-362, aunque él mismo concluye: "However, the possibility that the «friend of the bridegroom» alludes to the best man cannot be completely eliminated and gains more plausibility through the extended context than in the verse itself." (p. 362)

25 Cf. Mylène KemPter, "La signification eschatologique de Jean 3.29”, New Testament Studies 54 (2008) 42-59, quien sin embargo también cuestiona la identificación del "amigo del esposo"y el shoshebin.

26 Sigo aquí a AlONSO SCHÖKel, Simbolos matrimoniales, 35-37; y a Jocelyn McWhirTer, The Bridegroom Messiah and the People of God. Marriage in the Fouth Gospel (SNTS.S 138), Cambridge, Cambridge University Press, 2006, 53-56. En cambio, decía Joachim Jeremias, vú $\mu \phi \eta$, Grande Lessico del Nuovo Testamento, VII, 1445; y después Luca Pedroli, "La teoria del ninfagogo", 129-130, entre otros, que la"voz del esposo" era el feliz anuncio a su amigo, desde el tálamo nupcial, de que la esposa había permanecido virgen hasta la noche de bodas. Sin embargo, esta hipótesis no goza de apoyaturas textuales, mientras que la alusión a Jeremías y la idea joánica de que los allegados a Jesús escuchan su voz (Jn 


\begin{tabular}{|r|l|l|}
\hline קול ששון וקול שמחה & $\begin{array}{l}\text { qol sasón weqol simháh } \\
\text { qol hatán weqol kaláh }\end{array}$ & $\begin{array}{l}\text { voz alegre y voz gozosa } \\
\text { voz del esposo y voz de la esposa }\end{array}$ \\
\hline
\end{tabular}

En Jeremías, la estrofa anuncia por tres veces, en negativo, la próxima destrucción de Jerusalén y la cuarta vez es, en positivo, promesa de nuevo inicio. En Jer 7,30-34, el profeta denuncia la infamia del culto idolátrico en el valle de Ben Hinnom, al sur de Jerusalén - la mítica Gehenna-, en el cual se llegaron a realizar sacrificios de niños. Dios responde con una condena sin paliativos. Ese mismo valle se llenará de cadáveres, todo será tristeza ya que no habrá bodas:"Haré que en las ciudades de Judá y en las calles de Jerusalén enmudezcan la voz alegre y la voz gozosa, la voz del novio y la voz de la novia, pues todo el país quedará desolado" $(7,34)$. El estribillo reaparece en el oráculo en el que Dios convierte la vida de Jeremías en un signo profético de la catástrofe que acecha (Jer 16). Jeremías no puede ni casarse, ni tener hijos ni hacer duelo, ni asistir a banquetes, ya funerarios ya nupciales pues, así dice el Señor, "he decido hacer desaparecer de este lugar, a vuestros propios ojos y en vuestros días, la voz alegre y la voz gozosa, la voz del esposo y la voz de la esposa" $(16,9)$. Por tercera vez en Jer 25,1-13, el profeta echa mano del estribillo para avisar del castigo. Puesto que Judá y Jerusalén han incurrido en idolatría, Dios va a enviar a Nabucodonosor, rey de Babilonia, de modo que desaparecerá" voz alegre, voz gozosa, voz del esposo y voz de la esposa" $(25,10)$. A estos tres usos negativos sucede un inesperado anuncio venturoso. Cuando ya parecía que todo está perdido, Jeremías, prisionero en el patio de la guardia $(33,1)$, emplea el estribillo en positivo. El profeta de Anatot, siempre paradójico, habla de dolor cuando aparentemente hay alegría, y anuncia la alegría cuando el sufrimiento es total. Un nuevo inicio es posible para la ciudad desolada. Dios hará que los cautivos vuelvan $(33,7)$ y los perdone de sus pecados $(33,8)$, Jerusalén se convertirá en un "nombre evocador de alegría" $(33,9)$. A la ciudad que ahora está desolada"sin personas ni ganados" $(33,10)$ volverá la "voz alegre y la voz gozosa, la voz del esposo y la voz de la esposa" $(33,11)$. Esta profecía se cumple primero en la vuelta del destierro, pero se abre al futuro de los tiempos mesiánicos, ya anunciados en Jer 33,15-18. Así pues, cuando el Bautista

5,25-26; 10,3-5.16.27; 16,13) hacen decantar la balanza en favor de la propuesta de Alonso Schökel. Así también Zumstein, Juan 1-12, 166, nota 34. 
dice que ha escuchado la voz del esposo y que"su alegría ha llegado

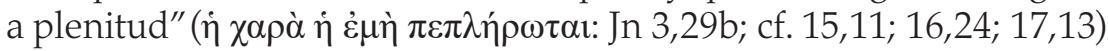
está sugiriendo al lector que Cristo es el Mesías esposo que ha inaugurado los tiempos nuevos anunciados por Jeremías y los demás profetas $^{27}$.

El argumento del Bautista sobre su identidad de amigo termina con un aforismo muy conocido:"es necesario que él crezca y que yo disminuya" (Jn 3,30). No hay competencia entre ambos. Jesús no es su rival, sino el esposo de cuya voz él se alegra. "Es necesario" ( $\delta \varepsilon \imath \hat{)}$ que sea así: es designio divino que Jesús gane discípulos y que Juan los pierda. Así se confirmará en Jn 4,1. De hecho, dos de sus discípulos ya han cambiado de maestro y han seguido a Jesús (1,35-39). Una vez que el esposo ha llegado a la alcoba, el amigo del novio les desea muchos hijos y se retira a su casa.

La intervención del Bautista continúa con un monólogo final (3,31-36) en el que Juan da su último testimonio sobre Jesús, recuperando algunas expresiones de la conversación previa de Jesús con Nicodemo, y abandonando la metáfora nupcial.

En conclusión, la simbología nupcial, de hondas raíces bíblicas, ha sido útil al evangelista para caracterizar a Jesucristo y delimitar las relaciones entre Juan y él. Obsérvese, sin embargo, que la caracterización esponsal no aparece en uno de los típicos dichos "Yo soy" del cuarto evangelio, sino en el comentario parabólico del Bautista. Será el lector el que deberá ir captando los matices de la cristología esponsal. A continuación, vamos a estudiar si es posible identificar la metáfora nupcial en otros pasajes anteriores y posteriores del cuarto evangelio.

\subsection{Prolegómenos de la simbología nupcial en Jn 1-2}

En Jn 2,1-11, Jesús realiza su primer signo en el contexto de unas bodas en Caná de Galilea. No podemos realizar un estudio pormenorizado

27 Otra profecía donde también aparecen unidos el motivo de la alegría, la metáfora nupcial y la esperanza escatológica es Is 62,5: "la alegría que encuentra el marido con la esposa, la encontrará tu Dios contigo". Por otro lado, el motivo de la alegría escatológica se repite en el cuarto evangelio a menudo: como anuncio profético en Abraham, que se alegró pensando en el día de Jesús (Jn 8,56), como anuncio inminente de la perfecta alegría de los discípulos $(15,11 ; 16,24 ; 17,13)$ y como realización, cuando ven al resucitado y se alegran (20,20; cf. 16,20-22; 1 Jn 1,$4 ; 2$ Jn 12). 
del pasaje, tan solo esclareceremos el valor de la simbología nupcial con relación a la posterior identificación en Jn 3,29 de Cristo como el Mesías esposo ${ }^{28}$. El relato, a diferencia de los milagros de los sinópticos, apenas repara en las palabras de Jesús o en la fe de los agraciados. El evangelista incide más bien en algunos elementos del relato que contribuyen a manifestar la gloria de Jesús y acrecentar la fe en él, finalidad última del pasaje $(2,11)$. Las vicisitudes concretas de la celebración de una boda en Caná, la falta de vino y la transformación del agua son presentadas como un signo para el lector, invitado a profundizar en su significado, como posteriormente la samaritana será invitada a pasar del agua del pozo al agua que salta hasta la vida eterna, o la multitud es exhortada a buscar no el pan que sacia su hambre física, sino el verdadero pan de vida. En esta búsqueda del "otro" sentido, la boda concreta de Caná remite a las bodas escatológicas, "símbolo del fin como tiempo de salvación"29, en las que Dios renovará la alianza con su pueblo y volverá a desposar a Israel "en justicia y en derecho, en misericordia y en ternura... en fidelidad" (Os 2,21-22; Is 54,4-8; 62,5, etc.). El elemento del vino abundante también es un motivo muy conocido en la tradición para significar la plenitud de los tiempos mesiánicos (Is 25,6; Am 9,13-14; Joel 4,18; 2 Baruc 29,3.5-6; 1 Henoc 10,19)³. Por tanto, Jesús asume en Caná

28 La bibliografía sobre este pasaje es enorme, mencionamos algunos estudios en diferentes lenguas: Jorg, FREY, "Das prototypische Zeichen (Jonh 2:1-11). Eine Kommentar-Studie", in R. Alan Culpepper - Jörg Frey (eds.), The Opening of John's Narrative (1,19-2,22) (WUNT 385), Tübingen, Mohr Siebeck, 2017, 165-216; Aristide SERrA, Le nozze di Cana (Gv 2,1-12): Incidenze cristologico-mariane del primo segno di Gesù (Bibliotheca Berica: In Domina Nostra 11), Padova, Messaggero, 2009.

29 Zumstein, Juan 1-12, 119.

30 Cf. la interesante presentación sobre el vino en la historia de la salvación de AndréVilleneuve, Nuptial Symbolism in Second Temple Writings, the New Testament and Rabbinic Literature. Divine Marriage at Key Moments of Salvation History (Ancient Judaism and Early Christianity 92), Leiden, Brill, 2016, 138-143. Por otro lado, también es sugerente el razonamiento de Brant PITRE, Jesus the Bridegroom: The Greatest Love Story Ever Told, New York (NY), Image, 2014, 46-48, según el cual el dicho de Jesús de Jn 2,4 ("mujer todavía no ha llegado mi hora") conecta el relato de las bodas de Caná con su muerte y resurrección (13,1-4). Esta conexión colorearía también de matices esponsales el don de la sangre de Cristo en la última cena. La mención del "amor hasta el extremo" de Jn 13,1 se referiría, así pues, al amor del Mesías esposo que da la vida por su esposa la Iglesia. Aunque muy bella, esta interpretación no tiene apoyaturas textuales: Jn 13 no posee un 
la función del novio: traer el vino bueno. El evangelista genera así una típica ironía entre el novio aparente de Caná, que a los ojos del mayordomo supuestamente ha guardado el vino bueno para el final $(2,10)$ y Jesús, el que verdaderamente provee el vino mejor, y que más adelante será identificado como el esposo verdadero (3,29-30). Este primer signo, en conclusión, ya sugiere que el verdadero esposo, el que trae el vino mejor, es Jesús. Seguidamente el pasaje Jn 3,22-30 lo declarará explícitamente.

Antes de continuar, algunos estudiosos proponen que otra expresión de la introducción del evangelio podría albergar una significación esponsal:"Juan les respondió: «Yo bautizo con agua; en medio de vosotros hay uno que no conocéis, el que viene detrás de mí, y al que no soy digno de desatar la correa de la sandalia" (Jn 1,26-27) ${ }^{31}$. En el antiguo Israel, existía una norma para tratar de perpetuar la herencia familiar: la ley del levirato. Según ella, el hermano o pariente más cercano de un difunto debía desposar a la viuda para proveer al fallecido con un hijo, que recibiera su herencia (cf. Deut 25,5-10; Gén 38; Rut 4). A veces existían problemas para determinar quién era el familiar que debía casarse con la viuda y el pariente más cercano también podía ceder la función a otro familiar, como sucede en el caso de Booz y Rut (Rut 4,6-8). Existía un rito para liberar a la viuda si el hermano del difunto no se casaba con ella, la halizah, que implicaba desatar o quitarle la sandalia. Y es que tener la sandalia era signo de posesión (Sal 60,10; 108,10). Según ello, cuando el Bautista dice que no es digno de desatar la correa de la sandalia a Jesús, no expresaría un gesto de humildad, sino que estaría evidenciando que el esposo legítimo de la esposa-pueblo era Jesús y no él. Algunos estudiosos dudan de que esta interpretación esponsal pudiera ser captada por los primeros oyentes del evangelio. Alonso Schökel dice que el evangelista recurre aquí al enigma retórico para introducir al lector

relato de la institución, por lo que la conexión entre Jn 2 y Jn 13 a partir del motivo del vino no se sostiene.

31 Aunque con pequeñas variaciones, el dicho está bien atestiguado: Mc 1,7; Mt 3,11; Lc 3,16; Jn 1,27; Hch 13,25; cf. Mt 22,23-24. Para la interpretación esponsal de la expresión, cf. Pierre ProulX - Luis Alonso SchÖKel, “Las Sandalias del Mesías Esposo", Biblica 59 (1978) 1-37; artículo abreviado en AlONSo ScHÖKEL, Símbolos matrimoniales, 109-121; SÁnchez-Navarro, "Gesù, il Messia Sposo", 6974; yVilleneuve, Nuptial Symbolism, 129-130. 
en el misterio mesiánico conyugal ${ }^{32}$. Con todo, el elemento esponsal no es desarrollado en el contexto cercano de Jn 1 . Habrá que esperar a las alusiones de las bodas de Caná y a la afirmación más explícita del Bautista en Jn 3,29. Entonces sí, tras una nueva lectura de todo el evangelio, el lector atento podrá evidenciar el significado profundo de esta alusión posible ${ }^{33}$.

\subsection{Desarrollos de la simbología nupcial en Jn 4, Jn 12, y Jn 20.}

Dice Luca Pedroli, que el signo inaugural de las bodas de Caná (Jn 2,1-11), el testamento del Bautista sobre Jesús como esposo (Jn 3,2230) y el encuentro de Jesús con la Samaritana (Jn 4,4-42) forman un "tríptico esponsal" que introduce todo el evangelio ${ }^{34}$. A nuestro modo de ver, esta propuesta da demasiada relevancia a la simbología nupcial en la obra. Usando un símil pictórico, la metáfora nupcial funciona en el cuarto evangelio como un color característico que matiza y da unidad al cuadro en su conjunto. No se trata del motivo principal, ni siquiera resulta evidente en una primera contemplación del cuadro, pero está presente y, si es identificada, enriquece el disfrute de la obra pictórica. Otros motivos simbólicos son mucho más relevantes (la vida, la luz y las tinieblas, la gloria, etc.), pero es cierto que las

32 ProulX-Alonso SchÖKel, “Las Sandalias del Mesías Esposo”, 23.

33 La recepción patrística sacará partido a la conexión entre la expresión del Bautista y la ley del levirato y llegará a hacer una relectura alegórica, con interesantes consecuencias eclesiales y misionales. Así dice, por ejemplo, Cesáreo de Arlés:"Esta figura se cumplió en los Apóstoles, pues muerto el hermano, es decir Cristo, que había dicho: «Id y anunciad a mis hermanos» (Mt 28,10), tomaron la esposa, o sea, la Iglesia. Así dice el apóstol Pablo: «Por el evangelio para Cristo Jesús os he engendrado» (1 Cor 4,15). Sin embargo, cuantos nacieron de la Iglesia por la enseñanza de los apóstoles no se llaman «petrianos» ni «paulinianos», sino «cristianos». Así se cumple la figura de la esposa del hermano muerto anticipada en la ley. No obraron así los herejes [...]. Unos se llaman «donatistas», otros «maniqueos» $\mathrm{O}$ «arrianos» $\mathrm{O}$ «fotinianos». Como los heresiarcas no son esposos legítimos, imponen a la gente sus nombres, no el de Cristo" (CESÁreo de ArLés, Sermones 96,5 [De rubo et corrigia calciamenti]; CChSL 103,395-396; trad. Alonso SCHÖKEL, Símbolos matrimoniales, 128).

34 Cf. Luca Pedroli, "Il trittico sponsale di Giovanni (Gv 2,1-11; 3,29-31; 4,542)", e-Biblicum 1 (2013) 170 (163-177):" il mistero nuziale fa da sfondo all'intera narrazione di Giovanni". En este sentido también VilLENEuve, Nuptial Symbolism, 120-189, que relee gran parte del cuarto evangelio desde la simbología nupcial. Algunas de sus propuestas, sin embargo, carecen de apoyatura textual. 
alusiones a la metáfora nupcial añaden matices interesantes al conjunto.Vamos a tratar, a continuación, de identificar otros tres posibles usos de la simbología esponsal en el cuarto evangelio.

En el encuentro de Jesús con la Samaritana en el pozo de Jacob (Jn 4,5-42), la temática esponsal es traída a colación por Jesús:" «Anda, llama a tu marido y vuelve». La mujer le contesta: «No tengo marido». Jesús le dice: «Tienes razón, que no tienes marido: has tenido ya cinco, y el de ahora no es tu marido. En eso has dicho la verdad»" (4,16-18). Antes de este diálogo enigmático, los elementos esponsales ya eran perceptibles en la misma descripción de la escena: el encuentro de un hombre con una mujer en un pozo era un motivo esponsal en la tradición bíblica. En el Antiguo Testamento, son numerosas las historias que relataban este tipo de encuentros entre un varón viajero en tierra extranjera y una mujer que venía a sacar agua del pozo, historias que normalmente acababan en boda: el siervo de Abraham encontró en el pozo a Rebeca para Isaac (Gén 24,1-67); Jacob, que es mencionado por tres veces en Jn 4,5.6.12, encuentra en el pozo a su predilecta Raquel (Gén 29,1-20); Moisés conoce a Séfora también en un pozo (Éx 2,15$22)^{35}$. Ahora bien, la historia del encuentro de Jesús y la Samaritana se diferencia de la escena tipo: Jesús no es un joven casadero a la búsqueda de novia, ni la Samaritana es una joven que va al pozo a la hora acostumbrada, sino una mujer mayor que va a deshora a buscar agua y que ya ha tenido cinco maridos, sin ser ninguno realmente el suyo $^{36}$. Por ello, el encuentro con la Samaritana no acaba en promesa de matrimonio, sino en confesión de fe en el Mesías. El relato, así pues, se aparta de la escena tipo y comunica contenidos inesperados a través de su progresión narrativa. Al decir de Zumstein, "de una intriga que describe el nacimiento de una alianza por el encuentro de un hombre y una mujer al borde de un pozo, el relato se transforma

35 Cf. el análisis de la escena tipo del encuentro en el pozo en Robert Alter, L'arte della narrativa bíblica (Biblioteca biblica 4), Brescia, Queriniana, 2018, 6583; y la aplicación de la escena tipo a Jn 4 de Zimmerman, "Jesus — the Divine Bridegroom?", 363-365; Jean-Louis SKA, "Jesús y la Samaritana (Jn 4). Utilidad del Antiguo Testamento", en ÍDEm, El camino y la casa. Itinerarios bíblicos, Estella, Verbo Divino, 2005, 221-236.

36 El motivo de los cinco maridos ha sido tradicionalmente interpretado a partir de 2 Re 17,24-32 (cinco tribus, siete dioses), y Josefo, Antigüedades judías, 9,288 (cinco tribus y cinco dioses), como una referencia alegórica al sincretismo de los samaritanos que les llevó a dar culto a cinco divinidades paganas. Cf. las críticas de Michaels, Gospel of John, 247-248, a esta interpretación. 
en una intriga de revelación" ${ }^{\prime 37}$. Con todo, el matiz esponsal continúa presente en el segundo nivel de significado. Como ya se había dicho en 3,29, Jesús se revela aquí como el verdadero esposo, que la samaritana buscaba insatisfactoriamente. Además, este encuentro de salvación, producido en el contexto del agua, se revela fecundo. Recuérdese que una de las notas de la simbología nupcial en la Escritura era la fecundidad. Así, el encuentro de Jn 4 genera la familia de la fe: los samaritanos, hijos de Jacob, pero considerados paganos, dan ahora culto al Padre en espíritu y en verdad, gracias a Jesús ${ }^{38}$. El título final que dan a Jesús, "este es verdaderamente el Salvador del mundo" (Jn 4,42), revela la amplitud universalista de la revelación de Cristo, por medio de los motivos esponsales.

Otro pasaje en el que los matices esponsales, si bien de modo más tenue, podrían estar presentes es la escena de la unción en Betania (Jn 12,1-11). Ya el mismo gesto de la mujer que lava los pies a Jesús podía sugerir en la época ciertos tonos amatorios, pues era costumbre de la esposa lavar los pies de su marido. Así se desprende de un paralelo intertestamentario de la novela judía José y Asenet ${ }^{39}$.

Más concretamente, el relato tradicional de la unión en Betania, presente en los otros evangelios (Mc 14,3-9; Mt 26,6-13; Lc 7,36-50), es perfilado por el cuarto evangelista. En Jn 12,3 se añade la noticia de que "la casa se llenó de la fragancia del perfume". El elemento olfativo no estaba presente en la tradición. La asociación entre el nardo y la fragancia solo reaparece en el canon bíblico en Cant 1,12. Orígenes de Alejandría, en su comentario al Cantar ${ }^{40}$, ya identificó

37 Zumstein, Juan 1-12, 185.

38 Cf. McWhirTer, The Bridegroom Messiah, 75-76.

39 Cuando José llega a casa de su amada Asenet, se desarrolla el siguiente diálogo: "Asenet le dijo: «Ven, señor, entra en mi casa». Le tomó por su mano derecha y le condujo al interior de su mansión. Sentó a José en el sitial de Pentefrés, su padre, y trajo agua para lavar sus pies. José le dijo: «Que venga una de las doncellas y lave mis pies». Asenet le replicó: «De ninguna manera, señor: mis manos son tus manos y tus pies son los míos; ninguna otra te lavará los pies». Le convenció a la fuerza, y le lavó los pies. Tomó José la mano derecha de la joven y la besó repetidamente, y Asenet le besó a él en la cabeza. Llegaron de su hacienda los padres de Asenet y la vieron sentada con José, vestida con el traje de boda. Se alegraron por ello y glorificaron a Dios. Luego comieron y bebieron" (20,1-5; trad. Ramón Martínez Fernández - Antonio Piñero, Apócrifos del Antiguo Testamento, III, 228).

40 Cf. Orígenes, Comentario al Cantar de los Cantares, 2.9,1-9 (Biblioteca Patrística 51), Madrid, Ciudad Nueva, 2007, 182-184. Ann Roberts Winsor, A King is 
esta alusión con la que el evangelista pretendería recalcar el carácter esponsal de Jesús:

\begin{tabular}{|c|c|c|}
\hline Cant 1,12 Lxx & 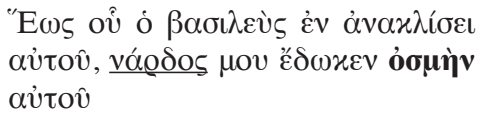 & $\begin{array}{l}\text { Mientras el rey estuvo en } \\
\text { su diván, mi nardo dio su } \\
\text { fragancia }\end{array}$ \\
\hline Jn 12,3 & 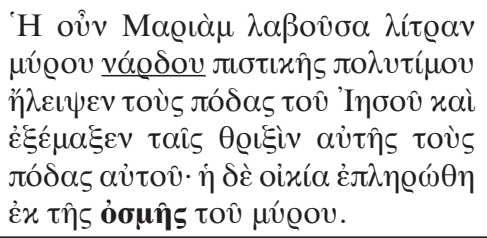 & $\begin{array}{l}\text { María tomó una libra de } \\
\text { perfume de nardo, auténtico } \\
\text { y costoso, le ungió a Jesús los } \\
\text { pies y se los enjugó con su } \\
\text { cabellera.Y la casa se llenó de } \\
\text { la fragancia del perfume. }\end{array}$ \\
\hline
\end{tabular}

Decíamos en el análisis sobre el Antiguo Testamento que la belleza y el simbolismo de la naturaleza, los perfumes, los vestidos y otros elementos eran típicos del uso bíblico de la metáfora nupcial. Aquí el motivo de la fragancia del nardo, tomada probablemente del Cantar de los Cantares, ayuda a caracterizar a Jesús con rasgos esponsales. Si esta alusión fue pretendida por el evangelista, la realeza mesiánica de Jesús - "mientras el rey estuvo en su diván..." - también sería reveladora. De hecho, Jesús es presentado como rey de Israel al inicio por boca de Natanael ("tú eres el Rey de Israel": Jn 1,49) y, más adelante, cuando las gentes lo proclamaron"rey de Israel" (12,12-19). Ahora bien, de nuevo como en el pasaje de la Samaritana, la tonalidad nupcial no deviene alegoría en la escena de la unción en Betania: María no es la esposa del Cantar, nada se dice de ella en este sentido. En cambio, la supuesta escena amatoria se transforma en anuncio pascual: ella no unge sus pies para el matrimonio, sino para la sepultura. El Rey esposo va a morir por amor. Su muerte, como la del grano de trigo (Jn 12,24-25; cf. 11,25-26), es necesaria para llevar a cabo su misión mesiánica. La cruz va a mostrar toda la grandeza del amor del esposo ${ }^{41}$.

Finalmente, Jesús también parece ser caracterizado con rasgos esponsales en la escena pascual de la aparición a María Magdalena (Jn 20,1.11-18). Es comúnmente aceptado hoy que el evangelista alude aquí al Cantar de los Cantares. En su relato de la pasión, el autor del cuarto evangelio añade un elemento novedoso respecto de los

Bound in the Tresses: Allusions to the Song of Songs in the Fourth Gospel (Studies in Biblical Literature 6), New York (NY), Peter Lang, 1999, cap. 2.

41 Cf. McWhirTer, The Bridegroom Messiah, 80-88. 
sinópticos: en un "huerto" arrestan a Jesús (Jn 18,1), en un"huerto"lo sepultan $(19,41)$ y allí la Magdalena lo busca confundiéndolo con el "hortelano" $(20,15)$. Con la mención del"huerto", el evangelista probablemente evoca este común escenario del Cantar (Cant 4,12.15$16 ; 5,1 ; 6,1-2.19 ; 8,13)$.

Más concretamente, María Magdalena (Jn 20,2.11-15), como la novia del Cantar, también busca apasionadamente al esposo cuando todavía estaba oscuro (Cant 3,1-4; 5,6; Jn 20,1), lo encuentra inesperadamente y lo abraza (Cant 3,4; In 20,14). Así pues, la escena nocturna de Cant 3,1-5 (LXx; cf. 5,2-8) sirve de modelo compositivo del relato del EvJn:

Sobre mi lecho en las noches ( $\dot{\varepsilon} v v v \xi i ̀ v)$

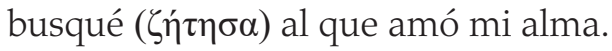

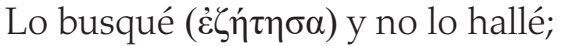

lo llamé y no me contestó.

“iMe levantaré pues y rondaré la ciudad

por las ágoras y por las calles,

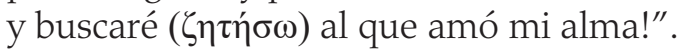

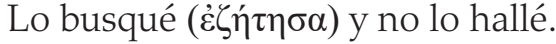

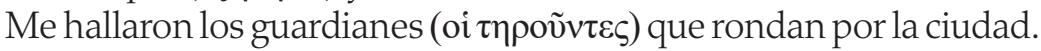

"Al que mi alma amó, ¿no lo visteis?

Fue apenas los pasé cuando hallé al que amó mi alma:

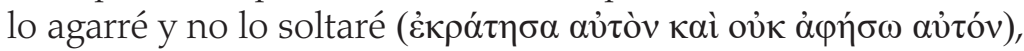

hasta llevarlo a casa de mi madre,

a la cámara de la que me concibió" ${ }^{\prime 2}$.

Sin embargo, como en los casos anteriores, el modelo bíblico es recibido creativamente y transformado en el relato evangélico. El encuentro entre Jesús y la mujer no conduce a la unión en el amor ("lo agarraré y no lo soltaré hasta llevarlo a la casa de mi madre": Cant

42 Los santos padres ya identificaron esta alusión de Jn 20,11-18 al Cantar de los Cantares. Cf. Rufino de Aquileya, Comentario al Símbolo apostólico 28 (CChSL 20,164; Biblia patrística 56,88); CirILO DE Jerusalén, Las catequesis 14,12 (Biblia patrística 67,311-312); etc. Preferimos citar a san Juan de la Cruz: “Cuando la esposa salió a buscar a su Amado por las plazas y arrabales, creyendo que los demás andaban en lo mismo, les dijo que, si lo hallasen ellos, le hablasen diciendo de ella cuánto penaba por su amor (Cant 5,8). Tal era la fuerza del amor de esta María, que le pareció que, si el hortelano le dijera dónde le había escondido, fuera ella y lo tomara, aunque más le fuera defendido" (Noche oscura, 2.13,7; BAC 14,553-554). 
3,4;"suéltame": In 20,17), sino que desemboca en la misión:"ve a mis hermanos y diles" (Jn 20,17). Además, Jesús les deja una promesa: Dios es su Padre. El anuncio de Jn 1,12-13 se cumple: los que creen en Jesús se convierten en hijos de Dios.

Obsérvese que, en las escenas precedentes, Jesús, en tanto que esposo, se encuentra con tres personajes femeninos: la Samaritana, María de Betania y María Magdalena. También en las bodas de Caná se encuentra con una mujer, su madre. La mayoría de estudiosos ha propuesto que, en el evangelio de Juan, la significación de estas mujeres excede sus límites biográficos y funcionan como figuras representativas ${ }^{43}$. Ellas representarían la respuesta de fe de los creyentes ante la manifestación del Mesías esposo. El referente de estas figuras femeninas simbólicas no debería ser definido con precisión ${ }^{44}$.Varios referentes son posibles: el pueblo judío, los samaritanos, la comunidad joánica, cada creyente, toda la humanidad, etc. Sin embargo, dichos actores no deben ser opuestos y distinguidos, so pena de perder el carácter simbólico de un evangelio que evita los contornos definidos y posibilita lecturas en diferentes planos.

\section{CONCLUSIÓN: SUGERENCIAS PARA UNA CRISTOLOGÍA ESPONSAL}

Recapitulamos y proponemos algunas constantes de los textos estudiados:

a) La metáfora nupcial y la identidad de Jesús. Los estudiosos discuten si la caracterización esponsal de Jesús en el cuarto evangelio atribuye a Jesús un rasgo propio de Yahvé en el Antiguo Testamento,

43 Según Adeline FeHriBaCh, The Women in the Life of the Bridegroom: A Feminist Historical-literary Analysis of the Female Characters in the Fourth Gospel, Collegeville (MN), Liturgical Press, 1998, "the women as helping to portray Jesus as the messianic bridegroom who was sent to establish familia dei" (p. 20), aunque no estoy de acuerdo con su conclusion de que "like most female characters in ancient texts, the female characters of the Fourth Gospel are marginalized after they fulfill their androcentric and patriarchal function" (p. 169).

44 En contra de lo afirmado por FeHRIBACH, Women in the Life of the Bridegroom, 161 ("Just as the Samaritan woman was bridge of the messianic bridegroom on behalf of the Samaritan people and Mary of Bethany was the bride of the messianic bridegroom on behalf of the Jews, now Mary Magdalene is bride of the messianic bridegroom on behalf of the entire community of faith"). Esta hipótesis resulta muy difícil de probar sobre todo para María de Betania. 
lo que sería indicio de una cristología alta; o ya existían tradiciones judías, previas a las elaboraciones de la Iglesia naciente, en las que "el esposo" comenzaba a ser un título mesiánico. La opinión clásica es que"en toda la literatura del tardo-judaísmo no existe ni siquiera un texto en el que la alegoría del esposo sea aplicada al Mesías" ${ }^{\prime 4}$. No obstante, nuevas investigaciones, basadas en una posible reinterpretación mesiánica del Sal 45 y del Cantar de los Cantares, han propuesto que la caracterización esponsal del Mesías sería un desarrollo judío anterior al uso de los seguidores de Jesús ${ }^{46}$. Con todo, estas evidencias no son concluyentes porque los textos citados suelen ser posteriores al siglo I y, lo que es más relevante, en el cuarto evangelio no hay ninguna alusión clara al Salmo 45, principal soporte de la supuesta tradición judía del Mesías esposo ${ }^{47}$. En cualquier caso, con Zimmermann me parece razonable no oponer los dos trasfondos:"se podría argumentar que el marcado contraste entre «divino» $\mathrm{o}$ «mesiánico» no encaja en el pensamiento joánico y podría ser engañoso en general. Un título mesiánico también podría superponerse con algunos aspectos de la «divinidad»" 48 . A veces los estudiosos exigen a los evangelistas un rigor que los textos esquivan. Precisamente en su capacidad de recibir tradiciones previas y reelaborarlas creativamente radica el poder evocador del EvJn para conducir al lector al misterio que anuncia. En conclusión, la cualificación esponsal de Jesús en el cuarto evangelio sugiere su mesianismo y asocia a Jesús con el misterio de Dios, invitando a los creyentes a establecer una relación de devoción y amor exclusivo con Jesús, el enviado del Padre.

b) La metáfora nupcial y la escatología. La metáfora nupcial en el cuarto evangelio no solo caracteriza a Jesús, también ubica al lector

45 Joachim Jeremias, vó $\mu \varphi \eta$, Grande Lessico del Nuovo Testamento, VII, 1447-1448.

46 Cf. McWhirTer, The Bridegroom Messiah, 106-120; RIESner, "The Question of the Baptist's Disciples”, 3313-3316, y Zimmerman, “Jesus — the Divine Bridegroom?”, 367-380. Los textos que estos autores citan como evidencia son, entre otros, el Targum de Salmos 45,3; el Targum de Zacarías 3,1-10; 4 Esdras 7,26, y algunos textos rabínicos.

47 Cf. las críticas de Judith Lieu, recensión a J. McWhiRTER, The Bridegroom Messiah, in Ecclesiology 5 (2009) 255-257, a la propuesta de McWhirter de que el Sal 45 funcionaría como "inner-text" de la metáfora esponsal en el cuarto evangelio.

48 Cf. Zimmerman,"Jesus - the Divine Bridegroom?", 380, quien cita en este sentido a Daniel Borarin, “Enoch, Ezra, and the Jewishness of «High Christology»", in Matthias Henze - Gabriele Boccaccini (eds.), Second Baruch: Reconstruction after the Fall (JSJSup 164), Leiden, Brill, 2013, 337-361. 
en el tiempo. Los motivos del banquete, del vino abundante y de la hora en el pasaje de las bodas de Caná (Jn 2,1-11), y la noticia de que la alegría del Bautista, el amigo del esposo, ha llegado a su plenitud $(3,22-30)$ comunican al lector que los tiempos mesiánicos han comenzado. A diferencia del dicho de los sinópticos sobre el ayuno, el esposo y su partida, la simbología esponsal en el cuarto evangelio recalca el ya de la salvación. Incide en una escatología realizada. De ahí que los elementos esponsales que salpican el evangelio emplacen al creyente a una urgente respuesta de fe. El fin ha comenzado: ¿de qué parte está él?

c) La metáfora nupcial y el acceso a Jesús. Tan importante como los contenidos que se deducen de la metáfora esponsal es el modo de acceso a ellos que la caracterización metafórica implica. Aparte de Jn 3,29, en que se compara a Jesús con el esposo, los demás pasajes que albergan matices esponsales, más o menos claros, son siempre alusivos y evocadores, no definidos y netos. Sin embargo, este tenor metafórico y elusivo de la cualificación esponsal de Jesús no es una rémora, tiene sus ventajas para el quehacer teológico: permite una cristología metafórica respetuosa, que intenta evitar la tendencia racionalista de una cristología muy clara en sus propuestas - para sortear el peligro de la herejía-, pero a la que se le hurta el poder evocador de la analogía para acceder al misterio. Las metáforas cristológicas son menos precisas que las afirmaciones dogmáticas, pero pueden abrir nuevas sendas de comprensión del misterio inefable de Jesucristo. Además, la caracterización esponsal de Jesús suma al interés legítimo de la cristología por las ideas la necesaria componente afectiva, emotiva y relacional. Conocer a Jesús no es solo saber sobre él, sino establecer una alianza de amor con él, alianza que implica intimidad, exclusividad y fecundidad, entre otras notas propias de la simbología nupcial.

d) La metáfora nupcial y la conexión entre cristología, eclesiología y soteriología. La caracterización esponsal de Jesús invita lógicamente a pensar en su esposa respectiva. Ya hemos dicho que el referente de la metáfora de la esposa no debe ser definido con contornos netos. Los diversos personajes femeninos del cuarto evangelio posibilitan diferentes identificaciones. De hecho, la historia de la recepción de los textos ha testimoniado muchas posibilidades: Israel, la Iglesia, el 
alma, la Virgen María, el místico, la consagrada, la humanidad, etc. ${ }^{49}$. En todas las opciones se espera una conexión íntima entre el amante y el amado; por ejemplo, entre Jesucristo y la Iglesia, en la identificación más típica. Esta evidencia invita a una cristología de corte más inductivo, en la que la experiencia de la comunidad de fe, esposa de Cristo, y de cada creyente, partícipe de su amor esponsal, sea tenida muy en cuenta ${ }^{50}$. En este sentido, la metaforización de la relación entre el Mesías y su pueblo mesiánico con rasgos esponsales implica la conexión entre la cristología, eclesiología, soteriología y espiritualidad. La esposa reconoce al esposo por el amor que ella recibe de él, dicho en otras palabras, por la salvación que reciben los creyentes en Cristo. Así pues, los contornos netos de los tratados teológicos dejan paso a la propuesta mistagógica más global del cuarto evangelio.

En la última página de la Biblia, el autor sagrado recurre a la simbología nupcial para expresar el ansia escatológica de la esposa Iglesia que, junto al Espíritu, claman:“iven!”(Apo 22,17). Las bodas del Cordero aún no se han consumado, por eso terminamos, como empezamos, con otra pieza de la liturgia bizantina, en este caso un tropario del Martes Santo, en el que se incide en la dimensión escatológica de la metáfora nupcial:

Amemos, hermanos, al Esposo, preparemos nuestras lámparas, encendidas de virtud y fe recta, para que, como las vírgenes sensatas del Señor, estemos preparados para entrar con él en las bodas; pues el Esposo, siendo Dios, a todos ofrece como don la corona incorruptible ${ }^{51}$.

49 Famoso, en este sentido, es el prólogo de Orígenes a su comentario al Cantar: "Este epitalamio, es decir, canto de bodas tengo para mí que Salomón lo escribió a modo de drama y lo cantó como si fuera el de una novia que va a casarse y está inflamada de amor celeste por su esposo, que es elVerbo de Dios. Lo cierto es que apasionadamente le ha amado, ya el alma, que fue hecha a su imagen, ya la Iglesia." (Comentario al Cantar de los Cantares, Prólogo 1,1; Biblioteca Patrística, p. 31). Estos dos modelos deben ser jerarquizados: el amor de Cristo a su Iglesia siempre debe preceder en la conciencia del creyente a su íntima relación de amor con Él.

50 Así propone Vives Pérez, "Cristo, esposo de la Iglesia", 126: "una cristología esponsal [...] aporta, al conjunto de la teología, el testimonio de la vida espiritual y de la santidad de la Iglesia como lugares teológicos propios y verdaderos (importancia de la llamada «teología vissuta dei santi» o «teología arrodillada»)".

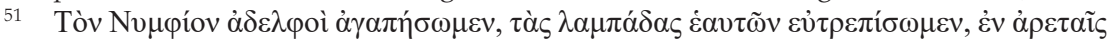

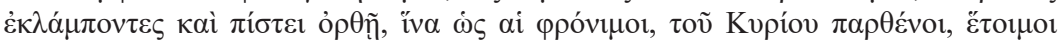

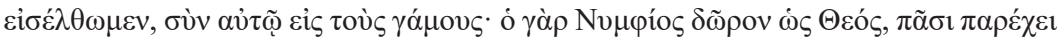

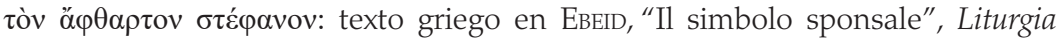
Sacra 22 (2016) 446 nota 76; la traducción es nuestra. 